\title{
Network dimensionalities and thermal expansion properties of metal nitroprussides
}

\author{
Tomoyuki Matsuda, ${ }^{a}{\text { Jungeun } \mathrm{Kim}^{b} \text { and Yutaka Moritomo }}^{*^{a}}$ \\ Received (in $X X X, X X X)$ Xth $X X X X X X X X X 20 X X$, Accepted $X$ th $X X X X X X X X X 20 X X$ \\ ${ }_{5}$ DOI: 10.1039/b000000x
}

We investigated the thermal expansion properties of metal nitroprussides, $M_{\mathrm{A}}\left[\mathrm{Fe}(\mathrm{CN})_{5} \mathrm{NO}\right] \cdot \mathrm{zH}_{2} \mathrm{O}\left(M_{\mathrm{A}}=\right.$ $\mathrm{Mn}, \mathrm{Fe}, \mathrm{Co}, \mathrm{Ni}, \mathrm{Cu}, \mathrm{Zn}$, and $\mathrm{Cd})$, which have various network structures, i.e. three-dimensional (3D) cubic ( $F m \overline{3} m$ for $M_{\mathrm{A}}=\mathrm{Fe}, \mathrm{Co}$, and Ni), distorted three-dimensional (distorted-3D) orthorhombic (Pnma for $M_{\mathrm{A}}=\mathrm{Mn}, \mathrm{Zn}$, and Cd), and two-dimensional (2D) orthorhombic (Amm2 for $M_{\mathrm{A}}=\mathrm{Cu}$ ) structures. In

10 the cubic system, in which the unbridged NO groups are randomly distributed, isotropic positive thermal expansion was observed. On the contrary, in the orthorhombic system, in which the unbridged NO groups are uniaxially distributed, positive (negative) thermal expansion was observed along (perpendicular to) the uniaxial direction. We interpreted the characteristic thermal responses in terms of the rotational vibrations of the $\left[\mathrm{Fe}(\mathrm{CN})_{5} \mathrm{NO}\right]$ units as well as their steric hindrances due to the network dimensionality.

\section{${ }_{15}$ Introduction}

Thermal expansion properties in network structures are attracting a considerable interest of the materials scientists, due to the possibility of zero/negative thermal expansion properties. ${ }^{1}$ Recently, coordination polymer frameworks are found to show 20 negative thermal expansion (NTE) behaviors. ${ }^{2-6}$ The NTE behaviors in such framework systems are generally attributed to the flexibility of the structure, in which thermal population of low-energy transverse and/or rotational vibrations of the molecular units. Such a flexibility of the lattice causes interesting ${ }_{25}$ physical properties, such as pressure-induced structural phase transition, ${ }^{7}$ pressure-induced amorphization, ${ }^{8}$ and large Grüneisen parameter. ${ }^{9}$ In addition, materials with NTE behaviors are useful in variety of electronics application and as components of highprecision thermometers.

30 Prussian blue type cyanides, $A_{x} M_{\mathrm{A}}\left[M_{\mathrm{B}}(\mathrm{CN})_{6}\right]_{y} \cdot \mathrm{zH}_{2} \mathrm{O}(\mathrm{A}=$ alkali metal ion, $M_{\mathrm{A}}=\mathrm{Mn}, \mathrm{Fe}, \mathrm{Co}, \mathrm{Ni}, \mathrm{Cu}, \mathrm{Zn}$ and $\mathrm{Cd}$, and $M_{\mathrm{B}}=\mathrm{Fe}, \mathrm{Co}$, $\mathrm{Pt}$ ) shows characteristic thermal expansion properties. ${ }^{4-6}$ The compounds belong to face-centered cubic $(F m \overline{3} \mathrm{~m} ; Z=4)$ structures, in which $M_{\mathrm{A}}$ and $M_{\mathrm{B}}$ are bridged by the cyano groups 35 and form a three-dimensional (3D) network structure. ${ }^{10}$ The alkali metal cations and water molecules are accommodated in the interstitial sites of the lattice. The thermal expansion coefficient ( $\beta \equiv \mathrm{d} \ln a / \mathrm{d} T$ ) of the lattice constant $a$ systematically decreases with an increase in $a$ : $\beta=+1.49 \times 10^{-5} \mathrm{~K}^{-1}$ for ${ }_{40} \mathrm{Rb}_{0.49} \mathrm{Co}\left[\mathrm{Fe}(\mathrm{CN})_{6}\right]_{0.80} \cdot 3.8 \mathrm{H}_{2} \mathrm{O}(a=9.943 \AA)$ and $\beta=-0.88 \times 10^{-5}$ $\mathrm{K}^{-1}$ for $\mathrm{Cs}_{1.00} \mathrm{Cd}\left[\mathrm{Fe}(\mathrm{CN})_{6}\right]_{1.00} \cdot 0.5 \mathrm{H}_{2} \mathrm{O}(a=10.755 \AA)$. The systematic change in $\beta$ is well explained by the thermally-induced rotational vibrations of the $\left[\mathrm{Fe}(\mathrm{CN})_{6}\right]$ units as well as their steric hindrances. According to this scenario, we may significantly 45 control the thermal expansion properties by the modification of the dimensionality of the cyano-bridged network.
In this work, we systematically studied the thermal expansion properties of metal nitroprussides, $M_{\mathrm{A}}\left[\mathrm{Fe}(\mathrm{CN})_{5} \mathrm{NO}\right] \cdot \mathrm{zH}_{2} \mathrm{O}\left(M_{\mathrm{A}}=\right.$ $\mathrm{Mn}, \mathrm{Fe}, \mathrm{Co}, \mathrm{Ni}, \mathrm{Cu}, \mathrm{Zn}$, and $\mathrm{Cd}$ ), in which one of the $\mathrm{CN}$ groups 50 are replaced by the NO group. The unbridged NO group modiied the dimensionality of the cyano-bridged network structure. Based on the structural analysis, we classified the network structure into three categories, i.e., $3 \mathrm{D}$ cubic $\left(F m \overline{3} m\right.$ for $M_{\mathrm{A}}=\mathrm{Fe}$, Co, and Ni), distorted three-dimensional (distorted-3D) orthorhombic (Pnma 55 for $M_{\mathrm{A}}=\mathrm{Mn}, \mathrm{Zn}$, and $\mathrm{Cd}$ ), and two-dimensional (2D) orthorhombic (Amm2 for $M_{\mathrm{A}}=\mathrm{Cu}$ ) structures. We found that the variation of the network dimensionality crucially influence the thermal expansion properties. We interpreted the dimensionalitydependence of the thermal expansion in terms of the rotational ${ }_{60}$ vibrations of the $\left[\mathrm{Fe}(\mathrm{CN})_{5} \mathrm{NO}\right]$ units as well as their steric hindrances.

\section{Experimental}

Powders of $M_{\mathrm{A}}\left[\mathrm{Fe}(\mathrm{CN})_{5} \mathrm{NO}\right] \cdot \mathrm{zH}_{2} \mathrm{O}\left(M_{\mathrm{A}}=\mathrm{Fe}, \mathrm{Co}, \mathrm{Ni}, \mathrm{Cu}, \mathrm{Zn}\right.$, and $\mathrm{Cd})$ were prepared by reacting an aqueous solutions of ${ }_{65} \mathrm{MnCl}_{2} \cdot 4 \mathrm{H}_{2} \mathrm{O}, \quad \mathrm{FeCl}_{2} \cdot 4 \mathrm{H}_{2} \mathrm{O}, \quad \mathrm{CoCl}_{2} \cdot 6 \mathrm{H}_{2} \mathrm{O}, \quad \mathrm{NiCl}_{2} \cdot 6 \mathrm{H}_{2} \mathrm{O}$, $\mathrm{CuCl}_{2} \cdot 2 \mathrm{H}_{2} \mathrm{O}, \mathrm{ZnCl}_{2}, \mathrm{CdCl}_{2} \cdot 2 \cdot 5 \mathrm{H}_{2} \mathrm{O}$, and $\mathrm{Na}_{2}\left[\mathrm{Fe}(\mathrm{CN})_{5} \mathrm{NO}\right] \cdot 2 \mathrm{H}_{2} \mathrm{O}$. The precipitated powders were filtered and washed with water and then dried in air. Chemical compositions of the prepared samples were determined by inductively coupled plasma atomic 70 emission spectrometry (ICP-AES) for metal elements and standard microanalytical methods for $\mathrm{C}, \mathrm{H}$, and $\mathrm{N}$ elements. Elemental analyses showed that the formulas of the obtained compounds were $\mathrm{Mn}\left[\mathrm{Fe}(\mathrm{CN})_{5} \mathrm{NO}\right] \cdot 2.1 \mathrm{H}_{2} \mathrm{O} \quad$ (Mn), $\mathrm{Fe}\left[\mathrm{Fe}(\mathrm{CN})_{5} \mathrm{NO}\right] \cdot 5.0 \mathrm{H}_{2} \mathrm{O} \quad(\mathbf{F e}), \quad \mathrm{Co}\left[\mathrm{Fe}(\mathrm{CN})_{5} \mathrm{NO}\right] \cdot 5.4 \mathrm{H}_{2} \mathrm{O} \quad$ (Co), $75 \mathrm{Ni}\left[\mathrm{Fe}(\mathrm{CN})_{5} \mathrm{NO}\right] \cdot 5.8 \mathrm{H}_{2} \mathrm{O} \quad(\mathbf{N i}), \quad \mathrm{Cu}\left[\mathrm{Fe}(\mathrm{CN})_{5} \mathrm{NO}\right] \cdot 2.2 \mathrm{H}_{2} \mathrm{O} \quad(\mathbf{C u})$, $\mathrm{Zn}\left[\mathrm{Fe}(\mathrm{CN})_{5} \mathrm{NO}\right] \cdot 2.0 \mathrm{H}_{2} \mathrm{O} \quad(\mathbf{Z n}), \quad \mathrm{Cd}\left[\mathrm{Fe}(\mathrm{CN})_{5} \mathrm{NO}\right] \cdot 2.3 \mathrm{H}_{2} \mathrm{O}(\mathbf{C d})$, respectively: calculated wt\% for $\mathbf{M n}$ : $\mathrm{Mn}, 17.80$; Fe, 18.09; C, 19.45; N, 27.22; H, 1.37\%: found; Mn, 17.55; Fe, 18.10; C, 
19.48; N, 27.18; H, 1.31\%, calculated wt\% for Fe: Fe, 30.86; C, 16.60; N, 23.23; H, 2.79\%: found; Fe, 30.43; C, 16.71; N, 23.17; H, 2.53\%, calculated wt\% for Co: Co, 15.84; Fe, 15.01; C, 16.14; N, 22.58; H, 2.92\%: found; Co, 15.72; Fe, 15.02; C, 16.34; N, 5 22.34; H, 2.68\%, calculated wt\% for Ni: Ni, 15.17; Fe, 14.86; C, 15.98; N, 22.37; H, 3.02\%: found; Ni, 15.24; Fe, 14.85; C, 16.02; N, 22.23; H, 2.86\%, calculated wt\% for $\mathrm{Cu}$ : Cu, 19.91; Fe, 17.50; C, 18.82; N, 26.34; H, 1.39\%: found; Cu, 19.77; Fe, 17.78; C, 18.97; N, 26.32; H, 1.21\%, calculated wt\% for Zn: Zn, 20.60; Fe, 10 17.60; C, 18.92; N, 26.48; H, 1.27\%: found; Zn, 20.08; Fe, 17.46; C, 19.01; N, 26.46; H, 0.90\%, calculated wt\% for Cd: Cd, 30.40; Fe, 15.10; C, 16.24; N, 22.73; H, 1.25\%: found; Cd, 30.22; Fe, 15.27; C, 16.54; N, 22.62; H, 0.81\%.

In order to precisely determine $a$ and the space groups of the 15 above-synthesized metal nitroprsusides, $\mathrm{X}$-ray powder-diffraction patterns were measured at the synchrotron-radiation facility, SPring-8. First, powder samples were filled into $0.3 \mathrm{~mm} \phi$ glass capillary. The capillary was put on a Debye-Scherrer camera at the BL02B2 beamline of SPring- $8 .{ }^{11}$ The wavelength of the X-ray $20(\lambda \sim 0.5 \AA)$ was calibrated by the lattice constant of standard $\mathrm{CeO}_{2}$ powder. The sample temperature was controlled by the cooled nitrogen gas. The exposure time was $5 \mathrm{~min}$. The lattice constants of each compound were refined by the RIETAN-FP program, ${ }^{12}$ and the $2 \theta$ range used in the Rietveld analyses were $3^{\circ}-30^{\circ}$

\section{${ }_{25}$ Results and discussion}

\section{Materials}

The metal nitroprussids are known to show several types of crystal structures. ${ }^{13-30}$ We performed Rietveld analysis of the synchrotron-radiation X-ray powder diffraction patterns of the 30 obtained compounds, and found that the compounds are classified into three types of crystal structures according to the metal ion (Table 1). We show in Fig. 1 the prototypical diffraction patterns at $300 \mathrm{~K}$ together with the results of Rietveld refinements. In the inset of Fig. 1, we depicted schematic crystal structures.

35 The cubic compounds (Fe, Co, and Ni) show 3D network structures similar to the case of the Prussian blue analogues. Here, we note that the five cyano groups of $\left[\mathrm{Fe}(\mathrm{CN})_{5} \mathrm{NO}\right]$ are bridged to the neighboring $M_{\mathrm{A}}$ while the NO group is unbridged. ${ }^{27}$

On the contrary, the orthorhombic compounds ( $\mathbf{M n}, \mathbf{C u}, \mathbf{Z n}$, 40 and $\mathbf{C d}$ ) have rather complicated network structures (Fig. 2). The Mn, Zn, and Cd compounds show distorted-3D network structure. Within the $a b$ plane (Fig. 2a, left), $M_{\mathrm{A}}$ atoms are surrounded by four cyanide nitrogen atoms of $\left[\mathrm{Fe}(\mathrm{CN})_{5} \mathrm{NO}\right]$, forming cyano-bridged 2D layers $\left(M_{\mathrm{A}}-\mathrm{N}-\mathrm{C}-\mathrm{Fe}\right)$. Along the $c$ 45 axis (Fig. 2a, right), one side of $M_{\mathrm{A}}$ is coordinated to cyanide nitrogen atom of $\left[\mathrm{Fe}(\mathrm{CN})_{5} \mathrm{NO}\right]$, while the other side is coordinated to the oxygen atom of the water ligand. That is, the five cyano groups of $\left[\mathrm{Fe}(\mathrm{CN})_{5} \mathrm{NO}\right]$ are bridged to the neighboring $M_{\mathrm{A}}$, while the NO group is unbridged. Due to the steric ${ }_{50}$ confinements between the free $\mathrm{NO}$ group of $\left[\mathrm{Fe}(\mathrm{CN})_{5} \mathrm{NO}\right]$, and water ligand of $M_{\mathrm{A}}$, the cyano-bridged $M_{\mathrm{A}}$-Fe layers along the $a b$ plane are significantly distorted. The $\mathbf{C u}$ compound shows 2D network structure. Within the $a b$ plane (Fig. 2a, left), $\mathrm{Cu}$ atoms are surrounded by four cyanide nitrogen atoms of [ $\left.\mathrm{Fe}(\mathrm{CN})_{5} \mathrm{NO}\right]$. 55 Along the $c$ axis (Fig. 2a, right), however, both sides of $\mathrm{Cu}$ atoms are coordinated to the oxygen atoms of water ligands. That is, the four $\mathrm{CN}$ groups of $\left[\mathrm{Fe}(\mathrm{CN})_{5} \mathrm{NO}\right]$ are bridged to the neighboring $\mathrm{Cu}$ in the $a b$ plane while the remaining $\mathrm{CN}$ group and the NO group are unbridged along the $c$ axis. The cyano-bridged $\mathrm{Cu}-\mathrm{Fe}$ ${ }_{60}$ layers stack alternately along the $c$ axis, causing 2D network structure.

Table 1 Chemical composition, space group, lattice constant at $100 \mathrm{~K}$ for $M_{\mathrm{A}}\left[\mathrm{Fe}(\mathrm{CN})_{5} \mathrm{NO}\right] \cdot \mathrm{zH}_{2} \mathrm{O}$.

\begin{tabular}{ccccc}
\hline & $\begin{array}{l}\text { Space } \\
\text { group }\end{array}$ & \multicolumn{3}{c}{ Lattice constant / $\AA$} \\
& & $a$ & $B$ & $c$ \\
\hline $\mathrm{Mn}\left[\mathrm{Fe}(\mathrm{CN})_{5} \mathrm{NO}\right] \cdot 2.1 \mathrm{H}_{2} \mathrm{O}$ & Pnma & $14.0371(5)$ & $7.5464(2)$ & $10.4127(3)$ \\
$\mathrm{Fe}\left[\mathrm{Fe}(\mathrm{CN})_{5} \mathrm{NO}\right] \cdot 5.0 \mathrm{H}_{2} \mathrm{O}$ & $F m \overline{3} m$ & $10.3144(3)$ & - & - \\
$\mathrm{Co}\left[\mathrm{Fe}(\mathrm{CN})_{5} \mathrm{NO}\right] \cdot 5.4 \mathrm{H}_{2} \mathrm{O}$ & $F m \overline{3} m$ & $10.2501(2)$ & - & - \\
$\mathrm{Ni}\left[\mathrm{Fe}(\mathrm{CN})_{5} \mathrm{NO}\right] \cdot 5.8 \mathrm{H}_{2} \mathrm{O}$ & $F m \overline{3} m$ & $10.1537(2)$ & - & - \\
$\mathrm{Cu}\left[\mathrm{Fe}(\mathrm{CN})_{5} \mathrm{NO}\right] \cdot 2.2 \mathrm{H}_{2} \mathrm{O}$ & Amm2 & $7.2231(4)$ & $6.9700(4)$ & $10.0850(6)$ \\
$\mathrm{Zn}\left[\mathrm{Fe}(\mathrm{CN})_{5} \mathrm{NO}\right] \cdot 2.0 \mathrm{H}_{2} \mathrm{O}$ & Pnma & $13.8463(3)$ & $7.4099(2)$ & $10.3789(2)$ \\
$\mathrm{Cd}\left[\mathrm{Fe}(\mathrm{CN})_{5} \mathrm{NO}\right] \cdot 2.3 \mathrm{H}_{2} \mathrm{O}$ & Pnma & $14.2012(5)$ & $7.6830(3)$ & $10.5029(4)$
\end{tabular}
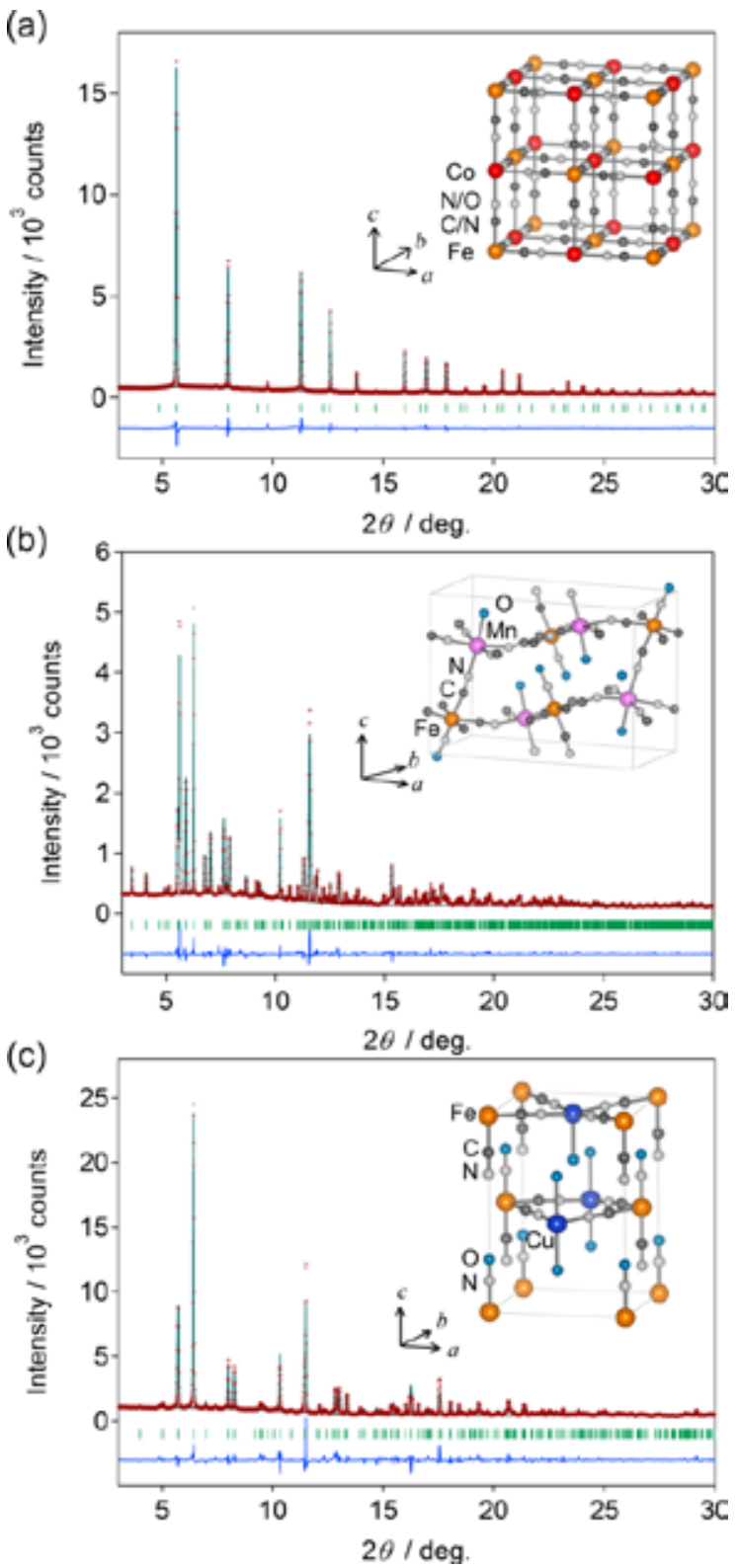
Fig. $1 \mathrm{X}$-ray powder diffraction patterns at $100 \mathrm{~K}$ and Rietveld analysis of Co (a), Mn (b), and $\mathbf{C u}$ (c). Red dots, black line, and blue line are the observed plots, calculated pattern, and their difference, respectively. Green bars represent the calculated positions of the Bragg reflections. 5 (inset) Schematic illustration of the unit cell.
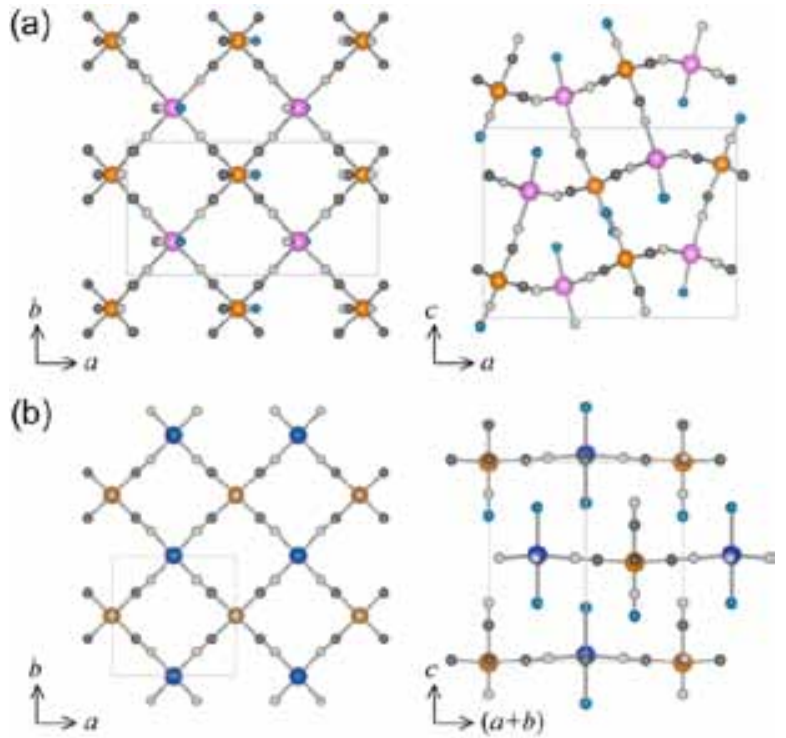

Fig. 2 Schematic crystal structures of distorted-3D network for $\mathbf{M n}, \mathbf{Z n}$, and $\mathbf{C d}$ (a), and 2D network for $\mathbf{C u}$ (b). (left) The projection in the $a b$ plane. (right) Network structure perpendicular to the $a b$ plane.

\section{${ }_{10}$ Thermal expansion properties}

We show typical examples of the magnified X-ray diffraction patterns around 422 reflection in Fe, Co, and Ni in Fig. S1 (ESI). The 422 reflection shifts to the high-angle side with decrease in temperature, reflecting PTE. The lattice constants were refined 15 against temperature. The reliable factor $R_{\mathrm{B}}$ ranges from 2.64 to $6.28 \%$. The temperature dependences of the normalized lattice constants are plotted in Fig. 3. We determined $\beta$ by the leastsquares fittings; $\beta=8.5 \times 10^{-6} / \mathrm{K}(\mathbf{F e}), 6.9 \times 10^{-6} / \mathrm{K}(\mathbf{C o})$, and $7.0 \times 10^{-6} / \mathrm{K}(\mathbf{N i})$.

(a)

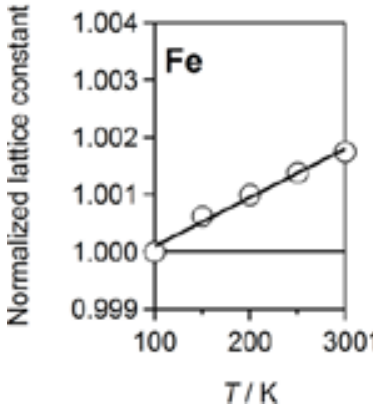

Fig. 3 Temperature dependences of the normalized lattice constants for $\mathbf{F e}(\mathrm{a}), \mathbf{C o}$ (b), and Ni (c). The lines are the results of the least-squares fittings.

Next, we show in Fig. S2 (ESI) typical examples of the 25 magnified X-ray diffraction patterns around 020, 311, and 212 reflections in $\mathbf{M n}, \mathbf{Z n}$, and $\mathbf{C d}$, which have distorted-3D networks. The 311 and 212 reflection shift to the high-angle side with decrease in temperature, reflecting positive thermal expansion (PTE). On the contrary, 020 reflection shifts to the
30 low-angle side with decrease in temperature, reflecting NTE along $b$ axis. The lattice constants are refined against temperature. The reliable factor $R_{\mathrm{B}}$ ranges from 1.01 to $2.80 \%$. To evaluate the thermal expansion of cyano-bridged $a b$ plane, we use the geometrical average of the lattice constants $\left(a^{\prime} \equiv a^{1 / 2} \times b^{1 / 2}\right)$. We 35 show the temperature dependences of $a^{\prime}$ and $c$ values in Fig. 4. We determined $\beta$ by the least-squares fittings. The $\beta$ values are $-9.8 \times 10^{-7} / \mathrm{K}\left(a^{\prime}\right)$, and $5.35 \times 10^{-5} / \mathrm{K}(c)$ for $\mathbf{M n},-4.3 \times 10^{-6} /$ $\mathrm{K}\left(a^{\prime}\right)$, and $5.19 \times 10^{-5} / \mathrm{K}(c)$ for $\mathbf{Z n}$, and $-3.4 \times 10^{-6} / \mathrm{K}\left(a^{\prime}\right)$, and $6.63 \times 10^{-5} / \mathrm{K}(c)$ for $\mathbf{C d}$.

(a)

(b)

(c)

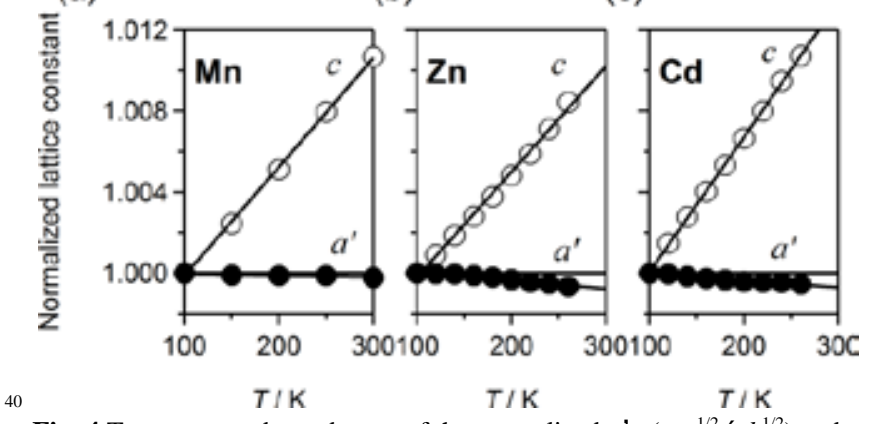

Fig. 4 Temperature dependences of the normalized $a^{\prime}\left(\equiv a^{1 / 2} \times b^{1 / 2}\right)$ and $c$ for Mn (a), Zn (b), and $\mathbf{C d}(c)$. The lines are the results of the leastsquares fittings.

We show in Fig. S3 (ESI) typical example of magnified X-ray ${ }_{45}$ diffraction patterns around 200, 020, 004, and 220 reflections in Cu, which have 2D network structure. The 020 and 004 reflection shift to the high-angle side with decrease in temperature, reflecting PTE along $b$ and $c$ axes. On the contrary, 200 and 220 reflections shift to the low-angle side with decrease in 50 temperature, reflecting NTE along $a$ axis and $a b$ plane. The lattice constants of $\mathbf{C u}$ are refined against temperature, and the reliable factor $R_{\mathrm{B}}$ ranges from 3.08 to $3.41 \%$. To evaluate the thermal expansion of cyano-bridged $a b$ plane, we use the geometrical average of the lattice constants $\left(a^{\prime} \equiv a^{1 / 2} \times b^{1 / 2}\right)$. We 55 show in Fig. 5 the normalized values of $\underline{a}^{\prime}$ and $c$ against temperature. We determined $\beta$ by the least-squares fitting, and the $\beta$ values are $-5.2 \times 10^{-6} / \mathrm{K}\left(a^{\prime}\right)$, and $1.20 \times 10^{-4} / \mathrm{K}(c)$

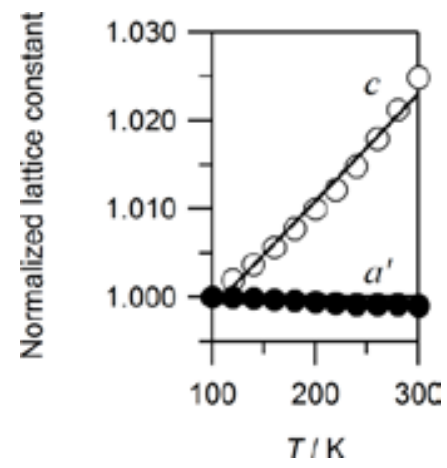

Fig. 5 Temperature dependence of the normalized $a^{\prime} \quad\left(\equiv a^{1 / 2} \times b^{1 / 2}\right)$ and $c$ 60 for $\mathbf{C u}$. The lines are the results of the least-squares fittings.

Relation between network dimensionalities and thermal expansion behaviors

Here, we discuss the relation between thermal expansion behavior and dimensionality. We plot the in-plane and out-of65 plane components of the thermal expansion against $M_{\mathrm{A}}$ for 
$M_{\mathrm{A}}\left[\mathrm{Fe}(\mathrm{CN})_{5} \mathrm{NO}\right] \cdot z \mathrm{H}_{2} \mathrm{O}$. The $\mathbf{F e}, \mathbf{C o}$, and Ni compounds show 3D network, the $\mathbf{M n}, \mathbf{Z n}$, and $\mathbf{C d}$ compounds show distroted-3D network, and the $\mathbf{C u}$ compounds shows 2D network.

In the in-plane components (Fig. 6a), the distorte-3D and 2D 5 systems show NTE, while the 3D system shows PTE. This dimensionality dependences of the thermal expansion is well understood by the steric hindrance effect. The origin of the NTE can be ascribed to the rotational vibrations of the $\left[\mathrm{Fe}(\mathrm{CN})_{5} \mathrm{NO}\right]$ units, analogous to the case of the Prussian blue analgoues. ${ }^{9}$ In 10 the distroted-3D and 2D systems, there exist enough spaces for the $\left[\mathrm{Fe}(\mathrm{CN})_{5} \mathrm{NO}\right]$ units to show thermally-induced rotational vibrations (Fig. 2). Then, the rotational vibration causes the NTE as observed. In the 3D system, however, the steric hindrance suppress the rotational vibration. Then, the inherent PTE 15 overcomes the NTE behavior.

In the out-of-plane components (Fig. 6b), the magnitude of PTE increases with decrease in the dimensionality. This is because the chemical bonds between the cyano-bridged layers become weaker as the dimensionality decreases. Actually, the 20 number $N$ of the cyano-bridge per one $\left[\mathrm{Fe}(\mathrm{CN})_{5} \mathrm{NO}\right.$ ] between the layers decrease from $1.67(=2 \times(5 / 6))$ for the 3D system, 1 for the distorted-3D system, and 0 for the $2 \mathrm{D}$ system. The reduction of the cyano-bridge weakens the inter-layer interaction, and enhances the PTE behavior.
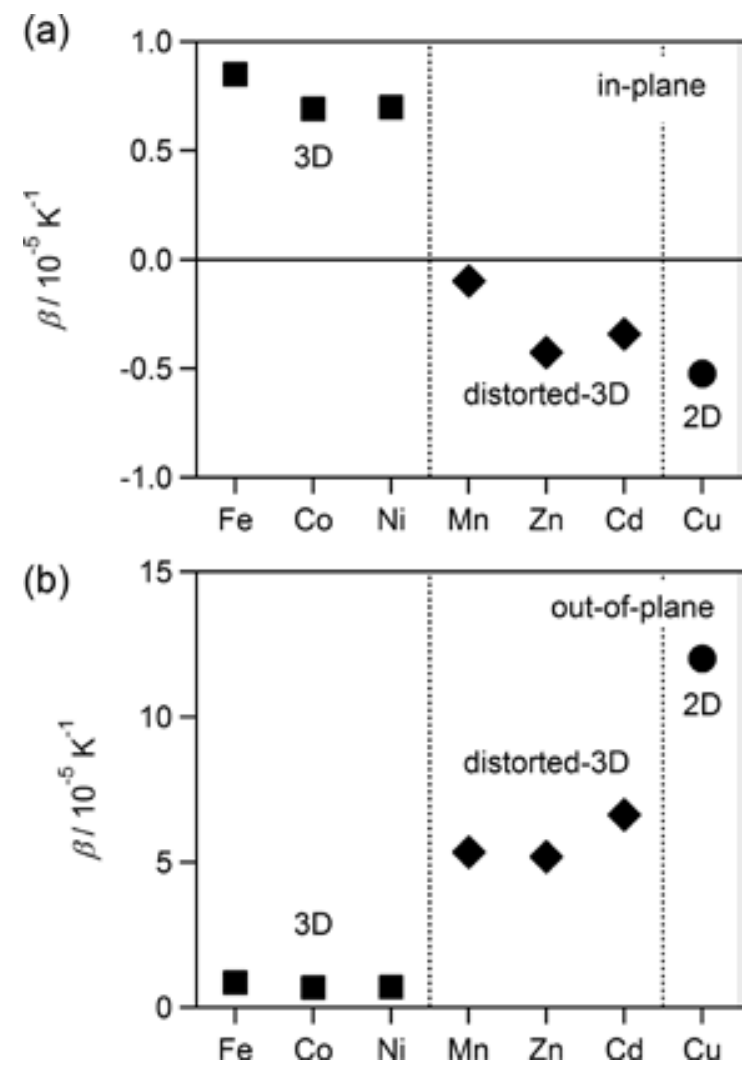

Fig. 6 (a) In-plane, and (b) out-of-plane components of the thermal expansion against $M_{\mathrm{A}}$ for $M_{\mathrm{A}}\left[\mathrm{Fe}(\mathrm{CN})_{5} \mathrm{NO}\right] \cdot \mathrm{zH}_{2} \mathrm{O}$. The $\mathbf{F e}$, Co, and $\mathbf{N i}$ compounds with 3D network (closed squares), the Mn, Zn, and Cd compounds with distorted- 3D network (closed diamonds), and the $\mathbf{C u}$ 30 compound with 2D network (closed circles).

\section{Conclusions}

In conclusion, we demonstrated that the anisotropic thermal expansion properties of the metal nitroprussides significantly depend on the dimensionality of the network structure. The 35 dimensionality dependence of the thermal expansion is well explained by the rotational vibrations of $\left[\mathrm{Fe}(\mathrm{CN})_{5} \mathrm{NO}\right]$ units as well as their steric hindrances. Here, we emphasize that the metal nitroprussides is a unique system, in which the dimensionality of the cyano-bridged transition metal network can be controlled by 40 chemical substitution of the $M_{\mathrm{A}}$ site.

\section{Acknowledgements}

This work was supported by a Grant-In-Aid for Scientific Research from the Ministry of Education, Culture, Sports, Science and Technology (No. 21244052). The synchrotron45 radiation X-ray powder diffraction experiments were performed at the SPring-8 BL02B2 beamline with approval of the Japan Synchrotron Radiation Research Institute (JASRI). Elementary analysis was performed at Chemical Analysis Division, Research Facility Center for Science and Engineering, University of ${ }_{50}$ Tsukuba.

\section{Notes and references}

${ }^{a}$ Graduated School of Pure and Applied Science, University of Tsukuba, Tsukuba, Ibaraki 305-8571, Japan. Fax: +81 29853 4337; Tel: + 8129 853 4337; E-mail:moritomo@sakura.cc.tsukuba.ac.jp

$55^{b}$ JASRI/SPring-8, 1-1-1 Kouto, Sayo-cho, Sayo-gun, Hyogo 679-5198, Japan.

† Electronic Supplementary Information (ESI) available: Temperature dependences of magnified X-ray powder diffraction patterns. See DOI: $10.1039 / \mathrm{b} 000000 \mathrm{x} /$

601 T. A. Mary, J. S. O. Evans, T. Vogt and A. W. Sleight, Science, 1996, 272, 90 .

2 A. L. Goodwin, M. Calleja, M. J. Conterio, M. T. Dove, J. S. O. Evans, D. A. Keen, L. Peters and M. G. Tucker, Science, 2008, 319, 794.

65 3. Y. Wu, A. Kobayashi, G. J. Halder, V. K. Peterson, K. W. Chapman, N. Lock, P. D. Southon and C. J. Kepert, Angew. Chem., Int. Ed., 2008, 47, 8929.

4 S. Margadonna, K. Prassides and A. N. Fitch, J. Am. Chem, Soc., 2004, 126, 15390.

705 K. W. Chapman, P. J. Chupas and C. J. Kepert, J. Am. Chem, Soc., 2006, 128,7009.

6 T. Matsuda, J.E. Kim, K. Ohoyama and Y. Moritomo, Phys. Rev. B, 2009, 79, 172302.

7 J. S. O. Evans, Z. Hu, J. D. Jorgensen, D. N. Argyriou, S. Short and

75 A. W. Sleight, Science, 1997, 275, 61.

8 C. A. Perottoni and J. A. H. da Jornada, Science, 1998, 280, 886.

9 R. Mittal, S. L. Chaplot, H. Schober and T. A. Mary, Phys. Rev. Lett., 2001, 86, 4692.

10 A. Ludi and H. U. Güdel, Struct. Bonding, 1973, 14, 1.

8011 E. Nishibori, M. Takata, K. Kato, M. Sakata, Y. Kubota, S. Aoyagi, Y. Kuroiwa, M. Yamakata and N. Ikeda, Nucl. Instrum. Methods Phys. Res. A, 2001, 467-468, 1045.

12 F. Izumi and K. Momma, Solid State Phenom., 2007, 130, 15.

13 L. Reguera, J. Balmaseda, C. P. Krap and E. Reguera, J. Phys. Chem. C 2008, 112, 10490.

14 J. B. Ayers and W. H. Waggoner, J. Inor. Nucl. Chem., 1969, 31 2045.

15 D. B. Brown, Inorg. Chem., 1975, 14, 2582.

16 L. A. Gentil, E. J. Baran and P. J. Aymonino, Inorg. Chim. Acta, 1976, 20, 251.

17 J. C. Long, J. L. Thomas and J. C. Lombardi, J. Inorg. Nucl. Chem. 1978, 40, 1627.

18 D. F. Mullica, E. L. Sappenfield, D. B. Tippin and D. H. Leschnitzer, Inorg. Chim. Acta, 1989, 164, 99. 
19 D. F. Mullica, D. B. Tippin and E. L. Sappenfield, Inorg. Chim. Acta, 1990, 174, 129.

20 D. F. Mullica, D. B. Tippin and E. L. Sappenfield, J. Coord. Chem., 1992, 25, 175.

521 E. Reguera, J. F. Bertrán, J. Miranda and A. Dago, Hyperfine Interact., 1993, 77, 1.

22 E. Reguera, A. Dago, A. Gómez and J. F. Bertrán, Polyhedron, 1996, 15, 3139.

23 Z. Z. Gu, O. Sato, T. Iyoda, K. Hashimoto and A. Fujishima, Chem. $10 \quad$ Mater., 1997, 9, 1092.

24 A. Benavente, J. A de Morán, O. E. Piro, E. E. Castellano and P. J. Aymonino, J. Chem. Cryst., 1997, 27, 343.

25 N. Machida, S. Ohkoshi, Z. J. Zhong and K. Hashimoto, Chem. Lett., 1999, 907.

1526 A. Gómez, E. Reguera and L. M. D. Cranswick, Polyhedron, 2001, 20, 165.

27 J. Balmaseda, E. Reguera, A. Gomez, J. Roque, C. Vazquez and M. Autie, J. Phys. Chem. B, 2003, 107, 11360.

28 M. Zentková, M. Mihalik, I. Tóth, Z. Mitróová, A. Zentko, M.

20 Sendek, J. Kováč, M. Lukáčová, M. Maryško and M. Miglierini, J. Mag. Mag. Mater., 2004, 272-276, e753.

29 J. T. Culp, C. Matranga, M. Smith, E. W. Bittner and B. Bockrath, J. Phys. Chem. B, 2006, 110, 8325.

30 E. Torres-Garcia, J. Balmaseda, L. F. del Castillo and E. Reguera, J. Therm. Anal. Calo., 2006, 86, 371. 